\title{
SACRIFICIAL PASTE FOR FABRICATION OF CERAMIC MATERIALS BY LAYER-BY-LAYER METHOD
}

\begin{abstract}
The aim of the work was to develop a sacrificial paste suitable for securing channels during shaping of ceramic materials with internal structures via combination of tape casting and soft lithography. Poly(ethylene glycol) methyl ether and polyethylene glycols with different molecular weight were selected as a main components of a sacrificial paste due to their compatibility to UV curable dispersion. The research shows that sacrificial paste should be characterized by proper melting point. This goal was achieved by using a composition of

PEG600 with $15 \mathrm{wt} . \%$ PEG20000 and $10 \mathrm{wt} . \%$ carbon. The invented sacrificial paste solidify beyond $27^{\circ} \mathrm{C}$ (melting point). After heating up to $80^{\circ} \mathrm{C}$ the viscosity of paste is low enough and easily fills the channels with diameter of $150-300 \mu \mathrm{m}$. What is more, the operational time during free cooling from $80^{\circ} \mathrm{C}$ to solidification is around 8 minutes what gives enough time for application. Carbon was added as a modifier of rheological properties and as a black dye that helps in visual evaluation of a degree of filling channel. The first test proved that proposed method of preparation of ceramic samples with application of invented sacrificial paste is reliable and can be practically applied.
\end{abstract}

Keywords: sacrificial paste, UV curing, soft lithography, tape casting, alumina

\section{Introduction}

In the last decade there has been growing demand for microfluidic devices such as microreactors. Typical microreactors consist of a network of micron-sized channels, which diameter is in the range $100-500 \mu \mathrm{m}$ and length can reach several centimetres. The application of microreactors is expected to have a number of advantages like high heat and mass transfer rate reactions as well as excellent thermal and chemical resistance. Thus, the reaction can be performed under more aggressive conditions with higher yields than it can be achieved with conventional reactors [1-4].

Generally metals, silicon, glass and polymers are widely used as a materials for microreactors fabrication. For these materials, the techniques for structuring and assembling are well known. However, these materials are often not suitable for reactions under harsh environments such as high temperatures and corrosive reactants. For example, polymers decomposed around $400-500^{\circ} \mathrm{C}$ while metals oxidized above $800^{\circ} \mathrm{C}$ in oxygen atmosphere. On the other hand, ceramics have several advantages over these materials such as good mechanical, thermal and chemical resistance, hardness, chemical inertness as well as catalytic activity of surfaces. For these reasons ceramic microreactors could be potentially useful in specific application.

Some methods of ceramic microreactor fabrication have been developed recently, such as rapid prototyping process chain [5], modified gelcasting procedure [6], modified solgel casting [7], injectable polymer-precursor technique [8], stereolithography [9], and low temperature co-fired ceramics (LTCC) $[10,11]$.

The ceramic microreactors can be also manufactured by combination of tape casting and soft lithography method. While tape casting is old and very well known shaping techniques, soft lithography still is not common method, especially in ceramics. Soft lithography refers to a collection of different techniques pioneered by Whitesides and his coworkers and offers a simple, low-cost route to micro and nanopattering of materials. The common feature of this class of techniques is the use of an elastomeric material with a patterned surface (so called stamp) [12-18].

In soft lithography and tape casting it is possible to apply the UV curable ceramic dispersion[19,21].Such combination allows instantly manufacturing of ceramic material containing internal structures such as channels, layer-by-layer without stacking of ceramic tapes and lamination process. However, successfully application of this method requires a proper securing of replicated patterns (channels) against being filled by ceramic dispersion of next casted layer. That is why the channels should be filled with special organic paste, which during sintering should be burnt out. These kind of paste is called sacrificial paste and is frequently used in LTCC techniques [22-24]. The sacrificial paste should be characterized by good wettability of substrate and viscosity low enough to fill every nook and cranny of replicated patterns. The aim of the study was to invent a sacrificial paste which will be match to the applied UV curing system (monomer and solvent) and which could be removed during sintering in the same temperature range.

\footnotetext{
* WARSAW UNIVERSITY OF TECHNOLOGY, FACULTY OF CHEMISTRY, 3 NOAKOWSKIEGO STR., 00-664 WARSAW, POLAND

* Corresponding author. falkowski@.ch.pw.edu.pl
} 


\section{Materials}

An alumina Almatis A16SG with an average particle size of $700 \pm 64 \mathrm{~nm}$ measured by DLS method was received from Almatis Company. The powders had purity of $99.7 \%$ with a density of $3.9 \mathrm{~g} / \mathrm{cm}^{3}$ measured on AccuPyc II 1340 Pycnometer and a specific surface area (SBET) of $8.28 \mathrm{~m}^{2} / \mathrm{g}$ on ASAP 2020. Poly(ethylene glycol) with average $M_{n} 400$ (PEG400) was purchased from POCH. Poly(ethylene glycol) with average $M_{n} 600$ (PEG600), poly(ethylene glycol) with average $M_{n} 20000$ (PEG2000) as well as poly(ethylene glycol) methyl ether with average $M_{n} 5000$ (mPEG5000) were purchased from Sigma Aldrich. The basic properties of glycol are given in TABLE 1. Irgacure 819 photoinitiator is a product of BASF. Glycerol monoacrylate (GM) was used as the monomer. The synthesis of the monomer has been described elsewhere [25]. A carbon CNR 115 used in this research was supplied by Cabot Norit Activated Carbon. The carbon has a form of pellets with $2 \mathrm{~mm}$ diameter. Poly dimethylsiloxane (PDMS) was used to fabricate an elastic polymeric stamp. PDMS (Sylgard 184 Silicone Elastomer Kit) was obtained from Dow Corning.

TABLE 1

Basic properties of glycols

\begin{tabular}{|c|c|c|c|c|}
\hline \hline & PEG400 & PEG600 & PEG20000 & mPEG5000 \\
\hline form & liquid & liquid/solid* & solid & solid \\
\hline $\begin{array}{c}\text { Melting } \\
\text { point } \\
{\left[{ }^{\circ} \mathrm{C}\right]}\end{array}$ & $4-8$ & $17-22$ & $63-66$ & $60-64$ \\
\hline $\begin{array}{c}\text { Molecular } \\
\text { weight } \\
{\left[\mathrm{M}_{\mathrm{n}}\right]}\end{array}$ & 400 & $570-630$ & $\begin{array}{c}16000- \\
24000\end{array}$ & 5000 \\
\hline
\end{tabular}

*depends on storage conditions

\section{Experimental}

\subsection{Preparation of UV curable dispersion of alumina}

The UV curable dispersions of alumina in mixture of PEG400 and glycerol monoacrylate were mixed in alumina jar in a planetary ball mill PM100 (Retsch) for 30 min with a speed of 300RPM. Glycerol monoacrylate to PEG ratio was $1: 1$. The alumina content in the dispersion was $42 \mathrm{vol} . \%$. The concentration of photoinitiator was $5 \mathrm{wt} . \%$ (based on the weight of synthesized monomer).

\subsection{Preparation of sacrificial paste}

A sacrificial paste was prepared by homogenization of carbon with glycols or mixture of glycols. In the beginning the carbon pellets was grinded in a planetary ball mill PM100 (Retsch) with a speed of 200RPM. Next, the glycols were heated up to $90-100^{\circ} \mathrm{C}$ and mixed with the powderized carbon. The concentration of carbon in mixture was varied from 5 to $15 \mathrm{wt} . \%$. The prepared compositions were mixed in a planetary ball mill PM100 (Retsch) with a speed of 300RPM for 15-20 minutes. The carbon in the SP plays two roles: dye added to white/transparent glycols and viscosity modifier.

\subsection{Preparation of PDMS stamp}

To prepare elastomeric stamps a prepolymer and a curing agent were mixed at a 10:1 weight ratio. After that, the mixture was degassed under reduced pressure in a vacuum desiccator. The process was held until air bubbles were removed. Then the mixture was poured on a master, degassed once again and placed in the laboratory dryer for curing for 2-3 hours at $100^{\circ} \mathrm{C}$. Afterwards the cured PDMS was peeled off from the master.

\subsection{Preparation of ceramic samples in green state}

Samples containing internal channels were prepared by combination of two methods: tape casting and soft lithography. In both techniques the same UV curable dispersion was used. At the beginning, an automatic coater MSK-AFA-I was used to produce tapes with thickness of $250 \mu \mathrm{m}$. After casting the tapes were UV cured. In such a way the substrate for next operation was obtained. If the thicker substrate was required, this step was repeated several times. To create the internal structures such as channels, the soft lithography was used. At first a layer of $250 \mu \mathrm{m}$ thickness was tape casted on the substrate. Then, the PDMS stamp with replicated pattern was pushed into the dispersion. The dispersion was UV cured through the stamp. After photopolymerization the PDMS stamp was peeled off and the replicated structures were filled by the heated up to $80^{\circ} \mathrm{C}$ sacrificial paste. The excess of paste was carefully removed and the surface of sample was cleaned. When sacrificial paste solidified, the next layers of the dispersion were casted and UV cured in a similar manner to the preparation procedure of substrate. A scheme of fabrication steps is presented in Fig 1.

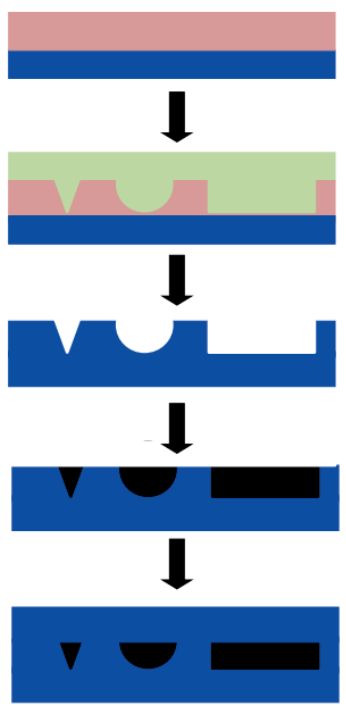

Substrate with UV curable dispersion

UV curing through a PDMS stamp which was pushed into dispersion

After UV curing the PDMS stamp is removed

The replicated structures (channels) are filled by sacrificial paste

Next layer of UV curable dispersion is tape casted and cured

Fig. 1 Scheme of fabrication steps 


\subsection{Rheological measurements}

A rheometer Kinexus Pro (Malvern, England) with plate-plate geometry was used for rheological measurements. A diameter of upper (rotating) geometry was $40 \mathrm{~mm}$ while a gap was set to $0.3 \mathrm{~mm}$. Two kinds of measurements were conducted. In the first type of measurements the shear rate was ramping up from 0.1 to $500 \mathrm{~s}^{-1}$. The measurements were carried out at $80^{\circ} \mathrm{C}$. In this temperature the glycols have liquid form. Each measurement was repeated three times. In the second type of measurements the glycols were heated to $80^{\circ} \mathrm{C}$. Then the temperature in rheometer software was set to $25^{\circ} \mathrm{C}$. During cooling the rheometer was measured the change of viscosity in time with constant shear rate of $1 \mathrm{~s}^{-1}$.

\subsection{Sintering}

Due to high content of organic phase in green samples a sintering process is a critical step in manufacturing of ceramic materials by proposed method. Based on TGA/DTA analysis of UV cured green tapes a sintering program was proposed. The sintering program is presented in TABLE 2.

TABLE 2

Sintering programme

\begin{tabular}{|c|c|c|c|}
\hline $\begin{array}{c}\text { Target } \\
\text { temperature }\left[{ }^{\mathbf{0}} \mathbf{C}\right]\end{array}$ & Action & $\begin{array}{c}\text { Rate } \\
{\left[{ }^{\mathbf{0}} \mathbf{C} / \mathbf{m i n}\right]}\end{array}$ & $\begin{array}{c}\text { Dwell time } \\
{[\mathbf{h}]}\end{array}$ \\
\hline 150 & Heating & 3 & \\
\hline 300 & Heating & 1 & \\
\hline 300 & Dwell & & 1 \\
\hline 700 & Heating & 1 & \\
\hline 1600 & Heating & 3 & \\
\hline 1600 & Dwell & & 1 \\
\hline 25 & Cooling & 5 & \\
\hline & \multicolumn{2}{|l}{} \\
\hline
\end{tabular}

\section{Results and discussion}

Shaping of samples with internal channels with a diameter of $\sim 200 \mu \mathrm{m}$ by combination of tape casting and soft lithography requires good protection of channel during casting of a cover (top layer). Otherwise the obtained channels could be deformed or even filled by UV curable dispersion and closed. That is why, the sacrificial paste (SP) should carefully fill every nook and cranny of the channels. So, it should have a good wettability of the substrate. So, it should have a good wettability of the substrate. Due to the fact that the UV curable dispersion includes in its composition PEG, the sacrificial paste based on PEG glycol should exhibit good properties. At the beginning the PEG600 with different concentration of carbon was used to prepare the SP. However, low melting point of this glycols caused that the refrigerator had to be used to induce solidification of paste. For this reason the application of mPEG5000 with higher melting point was investigated.

Fig. 2 shows viscosity curves at $80^{\circ} \mathrm{C}$ for mPEG500 and mixture of mPEG5000 with different concentration of carbon. Pure mPEG5000 and mPEG5000 with 5wt.\% carbon show low viscosity and exhibit Newtonian-like behavior. Such low viscosity is favorable because it enables fill the channels easily. In case of 10 and $15 \mathrm{wt} . \%$ of carbon the viscosity is much higher and the SP exhibit shear thinning behavior without the initial resistance to deformation. This type of behavior is known as pseudoplastic.

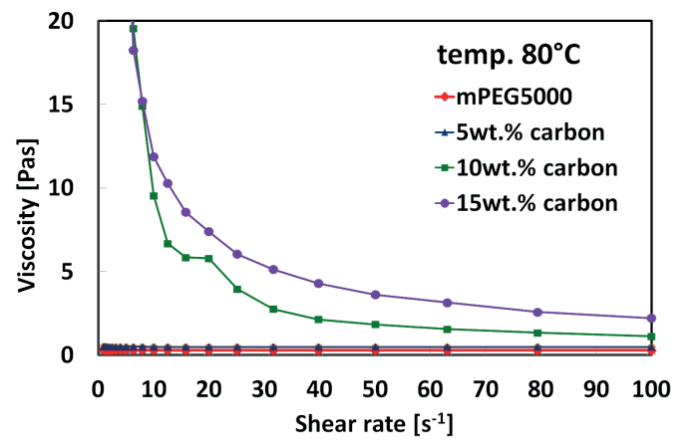

Fig. 2 The effect of carbon concentration on the viscosity of mPEG500 at $80^{\circ} \mathrm{C}$

However, the measurements of solidification during cooling down from $80^{\circ} \mathrm{C}$ to $25^{\circ} \mathrm{C}$ of mPEG5000 with addition of different concentration of carbon conducted on rheometer shows that the SP based on mPEG5000 solidify very quickly in 2,5 minutes (Fig. 3). Such short time is related with melting point of mPEG5000 $\left(60-64^{\circ} \mathrm{C}\right)$. Short solidification time does not allow for easy and accurate filling of channels, which prevents the application of such mixtures as a protective paste. It is possible to increase the solidification time but it will require heating the mPEG5000 to higher temperature e.g. $100-120^{\circ} \mathrm{C}$. Due to hand (manual) application of SP the high temperature is not favourable because poses a risk of severe burns. The carbon concentration does not affect the solidification time.

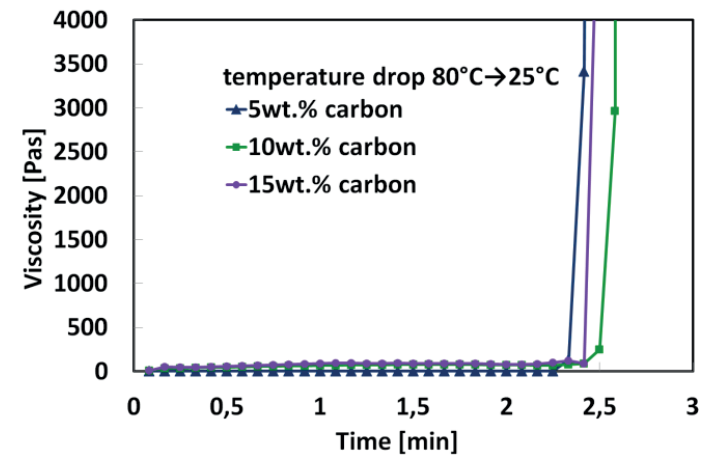

Fig. 3 Viscosity as a function of time during cooling down from $80^{\circ} \mathrm{C}$ to $25^{\circ} \mathrm{C}$ of mPEG5000 with addition of different concentration of carbon

Solidification time is related to melting point which depends on molecular weight. Polymers or glycols with lower molecular weight solidify in lower temperatures. For example the melting points of PEG400 and PEG600 are $4-8^{\circ} \mathrm{C}$ and $17-22^{\circ} \mathrm{C}$ respectively. To prepare the SP with increased solidification time it was necessary to find glycol with melting point between $30-40^{\circ} \mathrm{C}$. Due to many difficulties with finding of proper glycol it was decided to prepare the composition of two glycols. It was assumed that low molecular weight glycols will be responsible for low viscosity of the SP while the 
addition of glycol with higher molecular weight will increase melting point. The different compositions of PEG600 with PEG20000 were prepared and measured. Fig. 4 presents the viscosity as a function of shear rate for different mixtures of PEG600 - PEG20000 at $80^{\circ} \mathrm{C}$. It can be noticed that the addition of PEG20000 increases the viscosity of PEG600. Almost all mixtures show Newtonian-like rheological behaviour. However, the addition of carbon above 20wt.\% increased the viscosity above acceptable values. Further research on a practical application shows that too low viscosity is also not beneficial. That is why the mixture of PEG600 with 15wt.\% PEG20000 was selected as the most promising.

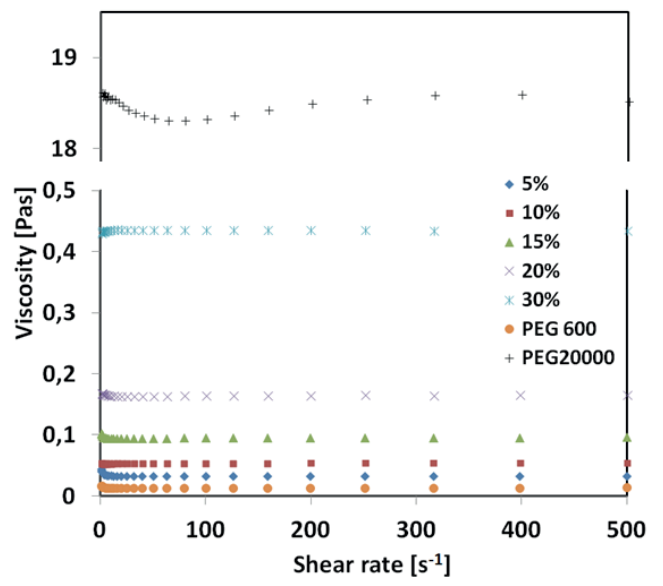

Fig. 4 Viscosity as a function of shear rate of different mixtures of PEG600 - PEG20000 at $80^{\circ} \mathrm{C}$

Fig. 5 shows viscosity curves for selected composition of PEG600 with PEG20000 with different concentration of carbon at $80^{\circ} \mathrm{C}$. It must be noticed that the curves for 5 and $10 \mathrm{wt} . \%$ of carbon overlap. What is more, the viscosity of mentioned mixtures was $\sim 0.16$ and $\sim 0.23$ respectively. These result are only $\sim 0.15 \mathrm{Pas}$ higher than for mixture without carbon addition (see Fig. 4). The addition of $15 \mathrm{wt} . \%$ of carbon increased the viscosity and change rheological characteristic from Newtonian-like to pseudoplastic which is not favourable for this application.

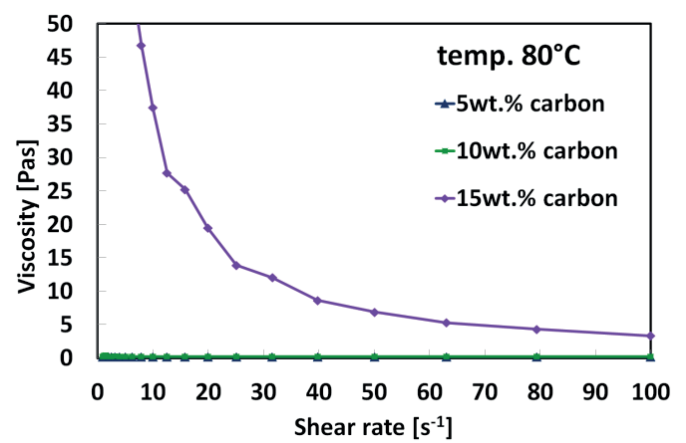

Fig. 5 Viscosity as a function of shear rate of PEG600 - 15wt.\% PEG20000 mixture with different concentration of carbon at $80^{\circ} \mathrm{C}$ (curves for 5 and $10 \mathrm{wt} . \%$ overlap)

The measurements of solidification during cooling down from $80^{\circ} \mathrm{C}$ to $25^{\circ} \mathrm{C}$ of PEG600-15wt.\%PEG20000 mixture with addition of different concentration of carbon conducted on rheometer are presented in Fig. 6. The investigated pastes showed longer solidification time than the pastes based on mPEG5000. In this case the carbon concentration does not affect the solidification time too. The way the viscosity changed indicates that solidification does not proceed homogeneously. When the solidification starts, the viscosity increases. In some point it can be observed sudden drop of viscosity followed by next increase of viscosity. Probably the structure of solidifying paste is just breaking by rotating geometry. The plateau of curves (above $5 \mathrm{~min}$. of measurement) is related with solidification of paste and with a sliding of rotating geometry onto a solidified surface.

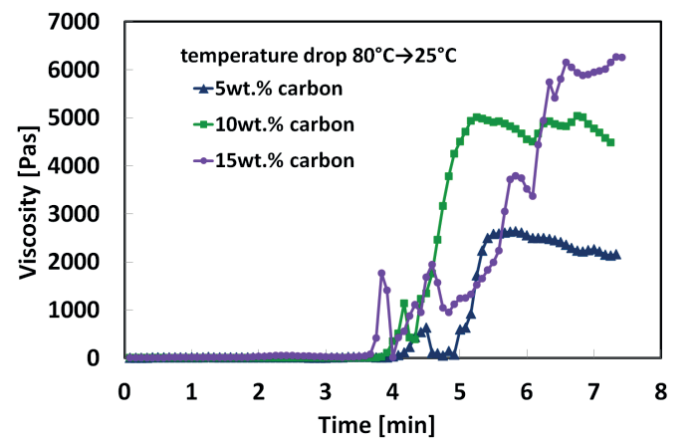

Fig. 6 Viscosity as a function of time during cooling from $80^{\circ} \mathrm{C}$ to $25^{\circ} \mathrm{C}$ of PEG600 - 15wt.\%PEG20000 mixture with addition of different concentration of carbon

The conducted experiments and a first trial of sacrificial paste application show that the best properties has PEG600 - 15wt.\%PEG20000 mixture with 10wt.\% carbon. This composition was used in further research. Fig. 7 presents viscosity and temperature of selected paste as a function of time during cooling down from $80^{\circ} \mathrm{C}$ to $25^{\circ} \mathrm{C}$. This research shows that the such compositions starts solidify at $27^{\circ} \mathrm{C}$ what corresponds with melting point. The solidification time is about $3.5 \mathrm{~min}$. However, the application of this SP shows that the real solidification time during laboratory work is twice longer. The comparison of solidification times measured by rheometer and by direct measurements of temperature (immersed thermometer) in $20 \mathrm{ml}$ of SP is presented in Fig. 8. This difference results from the operation of rheometer. When the target temperature is set the rheometer actively heat or cool the samples. It means that the temperature is changing as fast as possible until it reaches a preset value. What is more, a volume of sample is small due to small gap (in case of this research the gap was $300 \mu \mathrm{m})$. In laboratory work the prepared SP is not cooling actively, cooling occurs only by convection. Hence higher volume of SP will be cooled slower to some extent. The measurements of SP free cooling were performed until the surface of paste starts solidified. But it must be noticed that the tip of thermometer was immersed in the middle of samples, far from surface. During free cooling temperature gradient appears. The temperature inside the samples was higher than on the surface. So, the solidification temperature measured by thermometer during free cooling was around $45^{\circ} \mathrm{C}$. The real operational time is around 8 minutes what is more than enough.

The measurements of free cooling were also conducted for the pastes made of mPEG5000. Probably due to melting point around $63^{\circ} \mathrm{C}$ the obtained results were comparable to 
measurements done on rheometer. The solidification times increased around half minute.

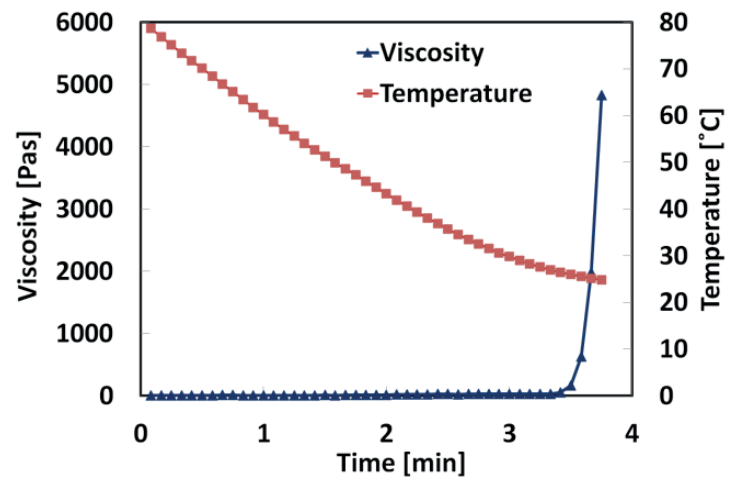

Fig. 7 Viscosity and temperature as a function of time during cooling down from $80^{\circ} \mathrm{C}$ to $25^{\circ} \mathrm{C}$ of PEG600 - $15 \mathrm{wt} . \%$ PEG20000 mixture with 10 wt.\% carbon

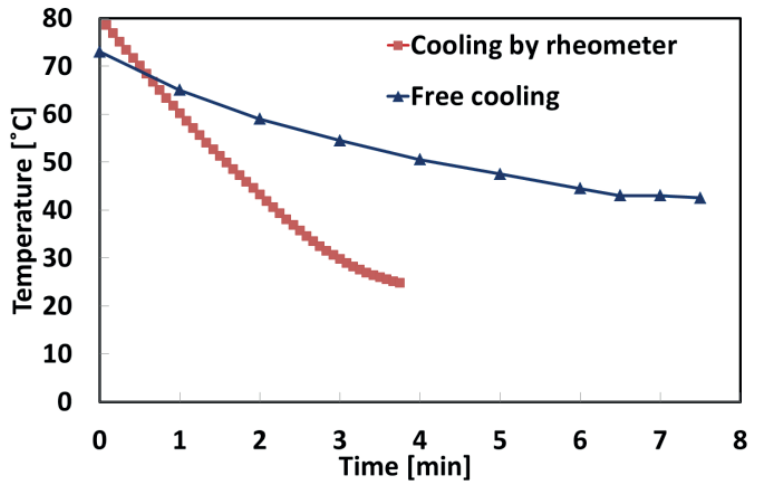

Fig. 8 Comparison between the cooling ways of PEG600 15 wt.\%PEG20000 mixture with $10 \mathrm{wt} . \%$ carbon

The prepared SP was used for shaping of ceramic samples with internal channels according to procedure described in section 3.4. Fig. 9 shows an image from light microscope of a cross section of green body in which a channel is secured by the sacrificial paste. This sample was composed from two layers of substrate, one layers with replicated pattern made by soft lithography and one layers that act as cover. It can be seen that the channel is secured precisely and there is no delamination between UV cured layers. Moreover, there is no signs that during casting of the top layer (cover) the UV curable dispersion poured into channel and closed them.

The obtained ceramic samples were sintered and cut. Due to the fact that the UV curable dispersion consist of PEG as well as the SP, the burning out of SP and organic phases from dispersion occurred in the same temperature regime. Hence, it was possible to apply the sintering program which was proposed for sintering of pure ceramic tapes prepared from UV curable dispersion. Fig. 10 presents an SEM images of cross sections of sintered sample with two magnifications. The adjacent layers in the sample are very well co-sintered without any signs of delamination. During sintering the SP was burning out leaving the empty channels.

To verify if the SP was burnt out from the whole channel in sample, the water was pumped through the channel. A free outflow of water from the outlet was observed.

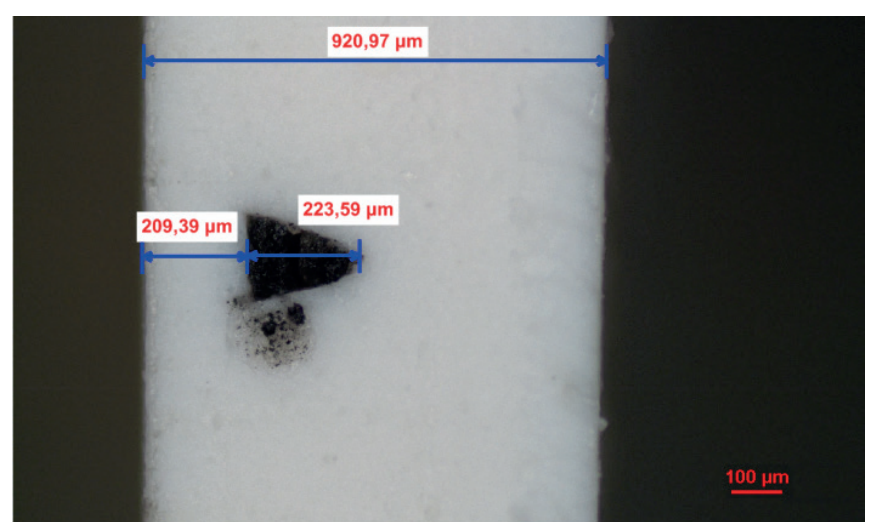

Fig. 9 An image from light microscope of a cross section of green body in which a channel is secured by the sacrificial paste

a)

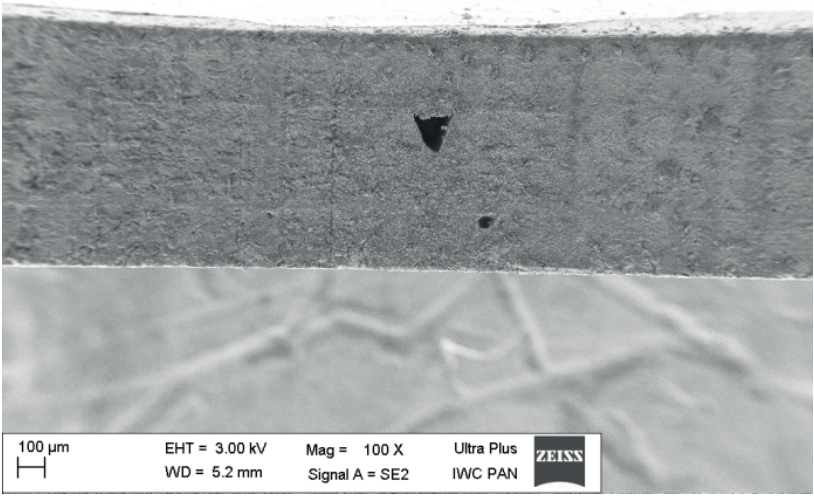

b)

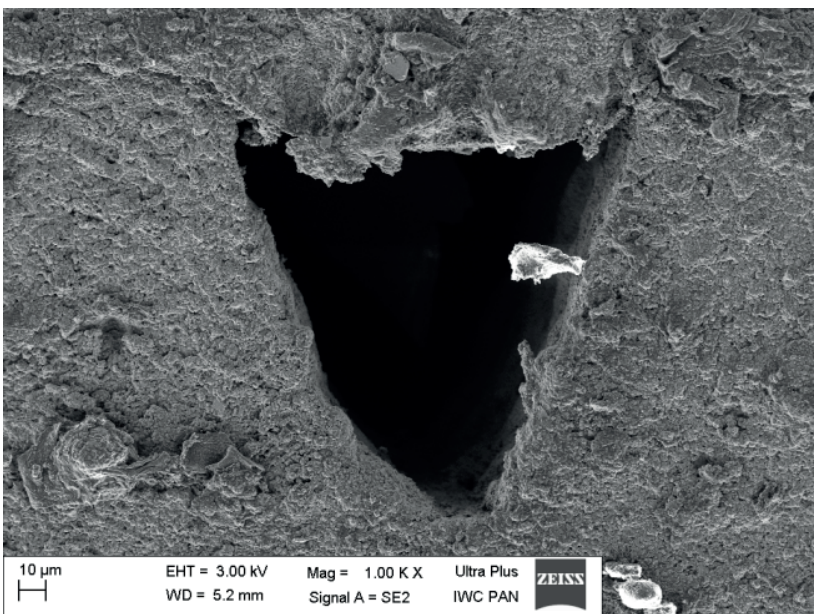

Fig. 10 SEM images of cross section of sintered sample a) magnification 100x; b) magnification 1000x

\section{Conclusions}

The conducted research allowed to develop the sacrificial paste for securing of channels suitable in layer-by-layer fabrication of ceramic samples by combination of soft lithography and tape casting.

The sacrificial paste should be characterized by proper melting point. Too low melting point caused that samples have to be cooled in refrigerator to solidify. Too high melting point shortens the application (operation) time or force to 
heat the paste to higher temperature what is inconvenient. For these reasons the sacrificial paste made of PEG600 with addition of PEG20000 was proposed. The addition of $15 \mathrm{wt} . \%$ of PEG20000 increase the melting point of PEG600 without significant viscosity increase.

The presence of carbon in the mixture modifies the rheological properties facilitating an application of paste. What is more, the carbon plays a role of a black dye. It is important technological aspect because the shaped samples are white as well as pure glycols (low molecular weight glycol are transparent). Hence, presence of carbon helps in visual evaluation of a degree of filling channel (see Fig. 9).

The simple test proved that proposed method of preparation of ceramic samples with application of invented sacrificial paste is reliable and can be practically applied.

\section{Acknowledgements}

This work was financially supported by Warsaw University of Technology.

The authors would like to thank:

- $\quad$ BTC Europe $\mathrm{GmbH}$ for free samples of Irgacure photoinitiators

- Almatis Company for free samples of alumina A16SG

\section{REFERENCES}

[1] N.Serra, T. Maeder, O. Gentsch, P. Ryser, Procedia Eng. 5, 874-877, (2010)

[2] W. Ehrfeld, V. Hessel, H. Löwe, Microreactors: New Technology for Modern Chemistry, 2000 WILEY-VCH Verlag $\mathrm{GmbH}$, Weinheim

[3] J. Némethné-Sóvágó, M. Benke, Mater. Sci. Eng., 39 (2), 89 101, (2014)

[4] D.M. Roberge, L. Ducry, N. Bieler, P. Cretton, B. Zimmermann, Chem. Eng. Technol. 28 (3), 318-323, (2005)

[5] W. Bauer and R. Knitter, J. Mater. Sci., 37 (15), 3127-40, (2002)

[6] C. Kenis, .J.A. Kenis, J. Am. Ceram. Soc. 90 (9), 2779-2783, (2007)
[7] C.M. Chan, G.Z. Cao, T.G. Stoebe, Microsys. Technol. 6, 200-204, (2000)

[8] Li-A. Liew, W. Zhang, V. M. Bright, L. An, M.L. Dunn, R. Raj,. Sensor. Actuat. A 89, 64-70, (2001)

[9] X. Zhang, X.N. Jiang, C. Sun, Sensor. Actuat. A 77 (2), 149 $156,(1999)$

[10] K. Malecha, L. J. Golonka, Microelectron. Reliab. 48, 866$871,(2008)$

[11] K. Malecha, L. J. Golonka, Microelectron. Reliab. 49, 585591, (2009)

[12] Y. Xia, G. M. Whitesides, Annu. Rev. Mater. Sci. 28, 153-84, (1998)

[13] Y. Xia, G. M. Whitesides, Angew. Chem. Int. Ed. 37, $550-$ $575,(1998)$

[14] S. K. Sia, G. M. Whitesides, , Electrophoresis 24, 3563-3576, (2003)

[15] D. Qin, Y. Xia, G. M. Whitesides, Nat. Protoc. 5, 491-502, (2010)

[16] D. Ye, P. Wang, Z.Ye, Y. Ou, R. Ghoshal, R. Ghoshal, T. Lu, Microelectron. Eng. 87, 2411-2415, (2010)

[17] J. J. Brandner, Fabrication of Microreactors Made from Metals and Ceramics in: T. Wirth, Microreactors in Organic Synthesis and Catalysis, 2008 WILEY-VCH Verlag GmbH \& Co. KGaA

[18] J. Wang ,G. Liu, Y. Xiong, X. Huang, Y. Guo, Y. Tian, Microsyst.Technol. 14, 1245-1249, (2008)

[19] T. Chartier, R. Penarroya, C. Pagnoux \& J. F. Baumard, Tape Casting Using UV Curable Binders, J. Eur. Cera. Soc. 17 (6), 765-771, (1997)

[20] P. Falkowski, A. Grzelak, Effect of solvents on curing process of photopolymerizable ceramic suspensions, Arch. Metall. Mater. 58 (4), 1411-1414, (2013)

[21] T. Chartier, C. Hinczewski, S. Corbel, . Eur. Cera. Soc. 19 (1) 67-74, (1999)

[22] H. Birol, T. Maeder, P. Ryser, J. Micromech. Microeng. 17, 50-60, (2007)

[23] K. Malecha, T. Maeder, C. Jacq, P.Ryser, Microelectron. Reliab. 51, 805-811, (2011)

[24] T. Maeder, C. Slater, B. Jiang, F. Vecchio, C. Jacq, P. Rysers, Inf. Midem-J. Microelectron. Electron. Compon. Mater. 42(4), $234-244,(2012)$

[25] C. Tallón, R. Moreno, M.I. Nieto, D. Jach, G. Rokicki, M. Szafran, J. Am. Ceram. Soc. 90, 1386-1393, (2007) 